Research paper

\title{
Cytolethal distending toxin producing Escherichia coli 0157:H43 strain T22 represents a novel evolutionary lineage within the 0157 serogroup
}

\author{
Domonkos Sváb ${ }^{\mathrm{a}}$, Balázs Bálint ${ }^{\mathrm{b}}$, Gergely Maróti ${ }^{\mathrm{c}}$, István Tóth ${ }^{\mathrm{a}, *}$ \\ a Institute for Veterinary Medical Research, Centre for Agricultural Research, Hungarian Academy of Sciences, Budapest, Hungary \\ b Seqomics Biotechnology Ltd., Mórahalom, Hungary \\ c Institute of Biochemistry, Biological Research Centre, Hungarian Academy of Sciences, Szeged, Hungary
}

\section{A R T I C L E I N F O}

\section{Article history:}

Received 24 June 2016

Received in revised form 14 October 2016

Accepted 3 November 2016

Available online 05 November 2016

\section{Keywords:}

Escherichia

O157:H43

CDT

LT-II

Comparative genomics

Phylogeny

\begin{abstract}
A B S T R A C T
Enterohemorrhagic Escherichia coli (EHEC) 0157:H7/NM strains are significant foodborne pathogens intensively studied, while other sero- and pathotypes of the 0157 serogroup only began to receive more attention. Here we report the first genome sequence of a cytolethal distending toxin (CDT-V) producing E. coli 0157:H43 strain (T22) isolated from cattle. The genome consists of a $4.9 \mathrm{Mb}$ chromosome assembled into three contigs and one plasmid of $82.4 \mathrm{~kb}$. Comparative genomic investigations conducted with the core genomes of representative $E$. coli strains in GenBank ( $n=62$ ) confirmed the separation of T22 from the EHEC and enteropathogenic (EPEC) 0157 lineages. Gene content based pangenome analysis revealed as many as 261 T22-specific coding sequences without orthologs in EDL933 EHEC 0157 prototypic and two phylogenetically related commensal E. coli strains. The genome sequence revealed 10 prophage-like regions which harbor several virulence-associated genes including $c d t$ and heat-labile enterotoxin (LT-II) encoding operons. Our results indicate that the evolutionary path of T22 is largely independent from that of EHEC and EPEC 0157:H7/NM strains. Thus, the CDT-producing T22 E. coli 0157:H43 strain represents a unique lineage of E. coli 0157.
\end{abstract}

C 2016 Published by Elsevier B.V.

\section{Introduction}

Enterohemorrhagic Escherichia coli (EHEC) 0157:H7/NM strains are significant food-borne zoonotic pathogens causing hemorrhagic colitis (HC) and haemolytic uraemic syndrome (HUS) in human (reviewed by Kaper et al., 2004). Typical EHEC strains produce a set of key virulence factors: one or more types of Shiga toxin (Stx) encoded by lambdoid prophages and intimin adhesin encoded by eae gene that is part of LEE pathogenicity island (reviewed by Caprioli et al., 2005). Besides the 0157:H7/NM serotypes, EHEC strains have been reported from various other serotypes, as well as members of the 0157 serogroup which also represent other pathotypes besides EHEC. E. coli 0157 strains harboring eae gene but no stx were categorized as enteropathogenic $E$. coli (EPEC), such strains were isolated from human and animal sources (Stephan et al., 2004; Tóth et al., 2009). Additionally, atypical 0157 strains, which carry none of the key virulence genes were reported (Sváb et al., 2013b; Tóth et al., 2009).

\footnotetext{
* Corresponding author at: Institute for Veterinary Medical Research, Centre for Agricultural Research, Hungarian Academy of Sciences, H-1143 Budapest, Hungária krt. 21., Hungary.

E-mail addresses: svab.domonkos@agrar.mta.hu (D. Sváb), balintb@seqomics.hu (B. Bálint), marotig@brc.hu (G. Maróti), toth.istvan@agrar.mta.hu (I. Tóth).
}

Because of the significance of EHEC and EPEC E. coli 0157:H7/NM strains as pathogens, several strains had their whole genome sequences published (Eppinger et al., 2013; Wyrsch et al., 2015). However, less attention has been devoted to atypical 0157 strains as well as strains with further serotypes exhibiting different $\mathrm{H}$ antigens (Hazen et al., 2013).

Cattle has been considered as a reservoir of Shiga toxin-producing $E$. coli (STEC) strains for a long time (Gyles, 2007). Earlier we reported atypical non-sorbitol fermenting E. coli 0157 strains with $\mathrm{H}$ antigens different from $\mathrm{H} 7$ isolated from the milk of healthy cattle, several of these strains produced cytolethal distending toxin (CDT-V; Tóth et al., 2009; Taieb et al., 2015). These findings indicated that similar 0157 strains could be persistent in the animal host, and the constant exchange of mobile genetic elements harboring virulence genes may give rise to new combinations of virulence traits. The emergence of novel pathotypes is a permanent potential epidemiological risk, as it was experienced recently in Germany where the largest outbreak of STEC was caused by recombinant enteroaggregative-heamorrhagic E. coli 0104:H4 (EAHEC) strains (Ahmed et al., 2012).

Earlier, we reported the draft genome of a CDT-V producing atypical E. coli 0157:H43 strain (T22, Sváb et al., 2013b). In the current study, our goals were to determine the complete genome of T22 and to investigate its phylogenetic relation to publicly available $E$. coli genomes. Comparative genomics revealed the unique genotype and phylogenetic position of T22 among E. coli strains. 


\section{Materials and methods}

\subsection{Bacterial strain}

E. coli strain 0157:H43 T22 was isolated from the milk of healthy cattle on a Hungarian dairy farm. See Tóth et al. (2009) for further procedure information.

\subsection{Whole genome sequencing}

Genomic DNA of E. coli T22 was isolated with GenElute Bacterial Genomic DNA Kit (Sigma-Aldrich) according to the manufacturer's instructions. Clone library was generated using Illumina Nextera Mate Pair Kit (Cat.Num.: FC-132-1001) per the manufacturer's instructions. Re-sequencing was performed on an Illumina MiSeq machine using V2 sequencing chemistry. Mate-paired reads were pre-processed following the manufacturer's recommendations (Data Processing of Nextera ${ }^{\circledR}$ Mate Pair Reads on Illumina Sequencing Platforms).

\subsection{Assembly, annotation and sequence homology search}

De novo assembly was performed with CLC Genomic Workbench 8.5.1 (CLC Bio) with contigs being subsequently arranged into scaffolds using SSPACE 3.0 (Boetzer et al., 2011). Gaps in scaffolds were closed with Spades v 3.1.1 (Bankevich et al., 2012) together with an in-house R script (unpublished results).

Annotation was performed with NCBI PGAAP.

Prophage regions in the genome were identified using PHAge Search Tool (PHAST, Zhou et al., 2011), and their automated annotation was manually curated. Sequence similarity searches were carried out using the publicly available tools of NCBI. Codon usage proportions were determined with the Cusp algorithm from the European Molecular Biology Open Software Suit (EMBOSS) package (Rice et al., 2000). The presence of virulence and antimicrobial resistance genes were also checked with Virulence Finder and ResFinder (Kleinheinz et al., 2014). Genes encoding secretion systems and associated effectors were investigated with the Effective database (Jehl et al., 2011).

\subsection{Pangenome analysis}

Complete genomes $(n=62)$ together with any associated plasmid sequences for representative $E$. coli and Shigella strains were downloaded from NCBI to assess the phylogenetic position of T22. Downloaded genomes as well as the T22 contigs were annotated using Prokka 1.10 (Seemann, 2014) to ensure identical gene prediction settings. Get homologues (Contreras-Monera and Vinuesa, 2013) was then applied on the annoted genbank files to identify clusters of orthologous sequences using the COGS clustering algorithm. The obtained pangenome matrix allowed gene content comparison between T22, two closely related commensal strains (IAI1, SE11) as well as the prototypic EHEC 0157:H7 EDL933 strain (GenBank no. CU928160.2, AP009240.1 and AE005174.2, respectively).

\subsection{Phylogenetic analysis of the core genes}

Get homologues (Contreras-Monera and Vinuesa, 2013) was used to compute the list of protein coding genes present in all strains (i.e. core genes). Clusters with inparalogues were excluded. Core gene DNA sequences were concatenated in the exact same order for each analyzed genome. Concatenated DNA sequences were then aligned using MAFFT (Tabei et al., 2008) with 100 bootstrapped alignment versions concomitantly generated with the "fseqboot" program from the EMBOSS package (Rice et al., 2000). Maximum likelihood phylogenetic trees were calculated from the original as well as from the bootstrapped alignment files using FastTree (Price et al., 2010). Support values based on 100 bootstrap replicates were added with "CompareToBootstrap.pl" script from the FastTree software package.

\section{Results and discussion}

\subsection{Basic features of the E. coli T22 genome}

The genome of $E$. coli 0157:H43 strain T22 consists of a $4.9 \mathrm{Mb}$ chromosome, and one circular plasmid (pT22) of $82.4 \mathrm{~kb}$ (GenBank accession number: LYNF00000000). The general features of the T22 genome are presented in Table 1. The chromosomal architecture of T22 is very similar to a number of other $E$. coli strains including pathogenic, commensals and K-12 laboratory strains. Another important feature of the chromosome is the high proportion (almost 7\%) of prophage sequences. The genome of T22 is assembled into three contigs containing 4687 coding sequences (CDS), 75 tRNA and 24 rRNA genes. In addition, the plasmid contains 79 protein coding genes. The present resequencing helped to finalize the previously published draft genome data (Sváb et al., 2013b) regarding the sizes of the chromosome and the plasmid of T22 (Table 1 ).

The plasmid termed pT22 belongs to the F replicon type, it harbors two genes of a multi-gene iron-di-citrate transport protein system, and carries a vapB-vapC toxin-antitoxin system.

\subsection{Prophage regions and associated virulence genes}

Because of the significant role of prophages as vectors of virulence genes and their dissemination among EHEC 0157 strains, we have paid special attention to the prophages harbored by E. coli T22. PHAST search and the annotation of the genome revealed that the chromosome of $E$. coli T22 contains 10 prophage regions (Table 2). Similarly to the prototypic EHEC 0157:H7 strains (Hayashi et al., 2001; Perna et al., 2001), a great number of prophages are identified and some of them also carry genes with virulence potential. The manual curation of the PHAST results revealed that prophages account for $339 \mathrm{~kb}$ in the genome, corresponding to almost $7 \%$ of the total chromosome length. Regarding the two EHEC 0157:H7 prototypic strains their genomes contain higher number of prophages: Sakai carries 12.2\% (Hayashi et al., 2001) and EDL933 11\% (Perna et al., 2002) prophage sequences. The size of these individual prophages varies between 13 and $52 \mathrm{~kb}$ and they are dispersed in the genome. The GC content of the prophages is between $45.5 \%$ and $52.6 \%$ and no codon usage bias can be detected when compared to the whole genome. This indicates adaptation of these prophage elements to the T22 host. The main characteristics of the identified prophages are summarized in Table 2, and Fig. 1 shows their schematic representations. We termed the prophages from T22 pp1 to T22 pp10. The architectures of the T22 prophages are different, three of them are lambdoid, three prophages are P2-like, and the remaining four are classified according to the closest homologue sequences (Table 2 ).

Homologies and their overall structure classify prophages T22pp4, T22pp6 and T22pp7 as P2-like prophages. T22pp6 harbors the operon encoding cytolethal distending toxin $\mathrm{V}$, and has been characterized earlier (Sváb et al., 2013a).

Table 1

Summary of main genomic features of E. coli T22.

\begin{tabular}{lll}
\hline & Chromosome & Plasmid \\
\hline Size (bp) & $4,875,355$ & 82,444 \\
Predicted coding CDSs & 4687 & 79 \\
GC \% & 51 & 49 \\
Coding regions \% & 88.5 & 70 \\
Average CDS length (bp) & 905 & 730 \\
tRNA & 75 & 0 \\
rRNA & 24 & 0
\end{tabular}


Table 2

Main characteristics of predicted prophage regions of E. coli T22.

\begin{tabular}{|c|c|c|c|c|c|c|c|c|c|c|c|}
\hline Designation & Contig & Start & End & $\begin{array}{l}\text { Length } \\
\text { (nt) }\end{array}$ & $\begin{array}{l}\text { GC } \\
\%\end{array}$ & $\begin{array}{l}\text { Assigned } \\
\text { type }\end{array}$ & $\begin{array}{l}\text { Upstream } \\
\text { flanking gene }\end{array}$ & $\begin{array}{l}\text { Downstream } \\
\text { flanking gene }\end{array}$ & $\begin{array}{l}\text { Virulence and fitness related } \\
\text { genes }\end{array}$ & Integrase & Repressor \\
\hline T22pp1 & 1 & 1 & 32,065 & 32,065 & 49.4 & PhiP27-like & Unknown & $\begin{array}{l}\text { tRNA 5' } \\
\text { methoxy-uridine } \\
\text { synthase }\end{array}$ & None identifed & Present & \\
\hline T22pp2 & 1 & 385,293 & 398,890 & 13,598 & 48.8 & none & Proline-tRNA & $\begin{array}{l}\text { type I secretion } \\
\text { system }\end{array}$ & None identifed & Present & \\
\hline T22pp3 & 1 & $1,480,783$ & $1,531,940$ & 51,158 & 49.3 & $\begin{array}{l}\text { Shigella } \\
\text { serotype } \\
\text { converting }\end{array}$ & Met-tRNA & $\begin{array}{l}\text { tmRNA binding } \\
\text { protein SmpB }\end{array}$ & None identifed & Present & $\mathrm{cl}$ and cro \\
\hline T22pp4 & 1 & $1,543,880$ & $1,574,799$ & 30,920 & 52 & P2-like & Ribosomal DNA & Yfi operon & None identifed & Present & $\begin{array}{l}\text { putative } \\
\text { cI }\end{array}$ \\
\hline T22pp5 & 1 & $1,703,290$ & $1,717,745$ & 14,456 & 49 & P4-like & $\begin{array}{l}\text { Sugar efflux } \\
\text { transporter B }\end{array}$ & Ser-tRNA & none identifed & Unidentified & \\
\hline T22pp6 & 1 & $2,288,961$ & $2,320,124$ & 31,164 & 52.6 & P2-like & fieF & срxP & CDT-V & Present & $\mathrm{c}$ and cox \\
\hline T22pp7 & 1 & $3,712,670$ & $3,744,641$ & 31,972 & 52.2 & P2-like & $\begin{array}{l}\text { TetR } \\
\text { transcriptional } \\
\text { regulator }\end{array}$ & $\begin{array}{l}\text { Trk } \\
\text { potassium-channel }\end{array}$ & None identifed & $\begin{array}{l}\text { Putative } \\
\text { int-like } \\
\text { protein }\end{array}$ & $\begin{array}{l}\mathrm{cI} \text { and } \mathrm{cII} \\
\text { regulator }\end{array}$ \\
\hline T22pp8 & 1 & $3,888,837$ & $3,928,433$ & 39,597 & 49.9 & Lambdoid & $\begin{array}{l}\text { Putative TEGT } \\
\text { family transport } \\
\text { protein }\end{array}$ & Ser-tRNA & Lipoprotein Bor & Unidentified & \\
\hline Т22pp9 & 2 & 350,924 & 396,041 & 45,118 & 45.5 & Lambdoid & $\begin{array}{l}\text { Cytosine } \\
\text { tRNA-synthetase }\end{array}$ & Unknown & $\begin{array}{l}\text { Lom-like protein, heat-labile } \\
\text { enterotoxin IIc1, E. coli } \\
\text { artAB-like AB toxin }\end{array}$ & Present & \\
\hline T22pp10 & 3 & 212,066 & 258,765 & 46,700 & 50.4 & Lambdoid & $\begin{array}{l}\text { Putative } \\
\text { transport } \\
\text { protein }\end{array}$ & $\begin{array}{l}\text { Starvation sensing } \\
\text { protein } \mathrm{rspB}\end{array}$ & Lom-like protein & Unidentified & \\
\hline
\end{tabular}

An important difference between these P2-likeprophages is that while T22pp6 has a P2-type regulatory switch consisting of $c$ and cox genes, prophages T22pp4 and T22pp7 contain the 186-type switch consisting of $c I$ and $c I I$ regulatory genes indicating that they appear to be more closely related to P2-like prophages of Salmonella origin, although P2-like phages are generally hypothesized to be host-specific (Nilsson et al., 2011).

Prophages T22pp8, T22pp9 and T22 pp10 show partial homologies to lambdoid prophages, particularly to Sp8 of the EHEC 0157:H7 Sakai strain (Hayashi et al., 2001), in the case of prophage T22pp8. T22pp9 contains a relatively conserved region, which also occurs in $\mathrm{Sp} 3$ and Sp10 of the Sakai strain.

T22pp9 also carries the gene cluster with genes encoding heat-labile enterotoxin type IIc1 (LT-IIc1). The region containing the toxin genes is situated downstream of the $Q$ antiterminator gene and also contains the artAB operon encoding the ADP-ribosyltransferase toxin homologue or pertussis-like toxin, first identified in Salmonella typhimurium (Saitoh et al., 2005), and later in $E$. coli strains, where it was termed eal $A B$, for E. coli art $A B$-like $A B$ toxin (Jobling, 2016). These two toxin-encoding operons are separated by three phage genes, encoding a putative membrane protein, a holin, and a hypothetical protein, respectively. It has already been proposed that LT-II is carried by prophages (Jobling and Holmes, 2012) and in the case of LT-IIa, a whole prophage genome was determined, and the carriage of a pertussis-like toxin gene cluster was also reported as prophage Rac-SA53 (Jobling, 2016). In T22pp9 the region carrying the LT-II toxin genes are very similar to that found in prophage Rac-SA53, however, most of the remaining structural regions of T22pp9 are significantly different. The lt-IIc1 and ealAB clusters harbored by T22 are $100 \%$ identical to those carried by E. coli strain NADC1036 (GenBank KU052040; Jobling, 2016).

Besides the above toxin genes, T22pp9 and alsoT22 pp10 carry an attachment invasion protein precursor gene, encoding the lom-like protein, which is thought to have a role in adhesion (Vica Pacheco et al., 1997), however, no recent studies have explored this function in details.

Serum resistance associated lipoprotein Bor (Barondess and Beckwith, 1995) encoding gene is present inT22pp8. This putative virulence factor is encoded by multiple lambdoid prophages found in several pathogenic E. coli strains, most notably in Stx-converting phages of EHEC strains (Asadulghani et al., 2009), T22pp1 is integrated into the
yecE-yecD site, which in some STEC strains contains prophage PhiP27, harboring the stx2e operon (Muniesa et al., 2000; Recktenwald and Schmidt, 2002). Within T22pp1 there are genetic stretches showing strong homology to parts encoding replication and packaging functions of PhiP27, suggesting evolutionary relationship between these prophages.

T22pp2, being only $11 \mathrm{~kb}$ in size, shows remarkable mosaic structure, but only low level homologies to known prophages. T22pp2 is integrated between a prolin tRNA gene and the operon encoding a type I secretion system. There are no reported examples of this insertion up to date, but the undisrupted region (prolin tRNA and type I secretion system in tandem) can be observed in the genome of several commensal strains.

The T22 prophages are integrated at different sites scattered across the genome, half of them are associated with tRNA genes (Table 2), which is in harmony with the findings of Bobay et al. (2013), who reported that prophages are frequently integrated next to tRNA genes.

The typical integration sites of Stx phages ( $w r b A, y e h V, s b c B, \arg W$ ) are intact in T22, with the exception of yecN-yecD containing T22pp1 noted above, providing potential integration sites for Stx phages.

\subsection{Additional virulence related genes}

Although the prophage pool carried by T22 differs greatly from the prophages carried by typical EHEC 0157:H7 strains, these regions also harbor several different ( $c d t$, lt-II, lpf) and identical (bor, lom) virulence genes (see Section 3.2). Additional virulence genes are also present in the chromosome, representing fimbriae and secretion systems (see below Sections 3.3.1-3.3.2).

\subsubsection{Fimbriae}

The initial PCR investigation of E. coli T22 showed that the strain harbors long polar fimbria (Lpf) genes (Tóth et al., 2009), this surface structure described by Torres et al. (Torres et al., 2002) was found to be harbored by a wide variety of pathogenic E. coli in the past decade, and proved to have adhesive functions in EHEC (Lloyd et al., 2012). Subtyping showed that the $\operatorname{lpf}$ operon harbored by T22 is of allelic type 2-1 (Sváb and Tóth, 2012), which is a widespread variant, but 
T22pp1

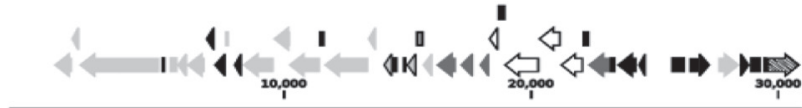

T22pp2

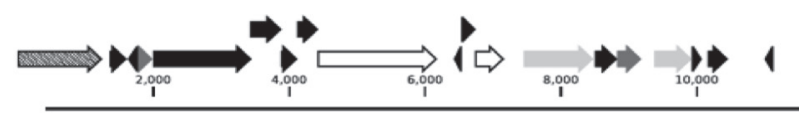

T22pp3

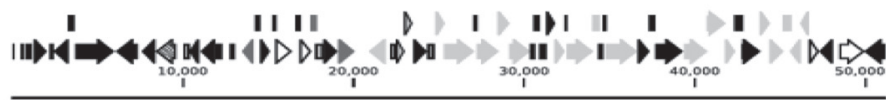

T22pp4

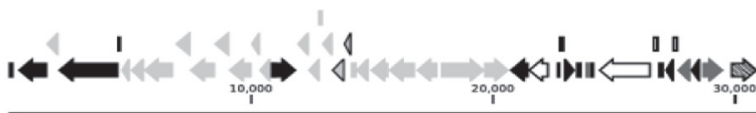

T22pp5

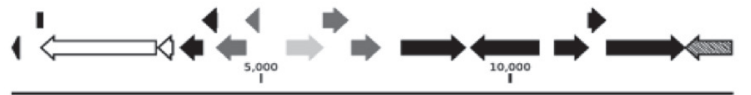

T22pp6

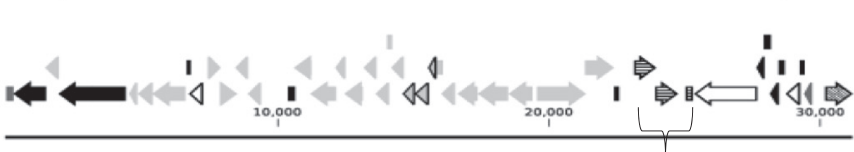
cdt-V

T22pp7

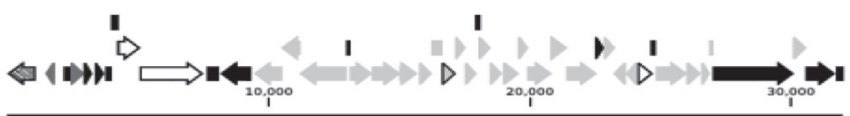

T22pp8

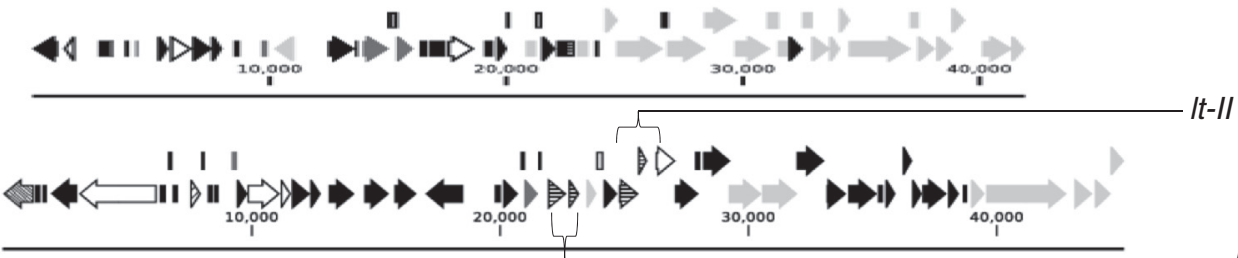

T22pp9

T22pp10

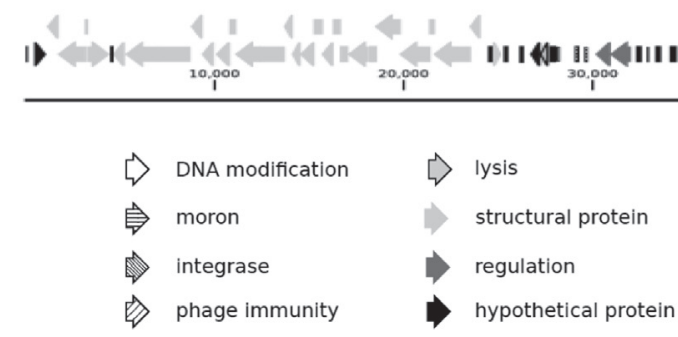

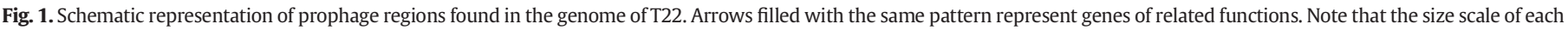

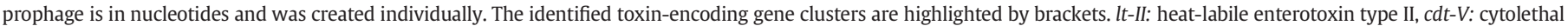
distending toxin type V, ealAB: Escherichia coli ArtAB-like toxin.

not characteristic for typical EHEC or EPEC 0157 strains (Torres et al. 2009).

E. coli T22 also carries the full operon of type 1 fimbriae encoded by the fim gene cluster, which is also a widespread virulence factor of pathogenic E. coli, especially uropathogenic E. coli (UPEC), where it plays a role in adherence to the urogenital epithelium, and can also be found in several commensal strains (Martinez et al., 2000).

Both fimbrial operons are integrated into their usual site, which is between the $\mathrm{glm}$ and pst gene clusters for lpf2-1, and between the $y \mathrm{hj}$ and gnt gene clusters for the fim operon, respectively.

\subsubsection{Secretion systems}

The T22 genome harbors a full type VI secretion system encoding gene cluster. This structure is considered to be a remnant of a bacteriophage tail, utilized by $E$. coli in the transport of various effectors (Leiman et al., 2009). This gene cluster carried by T22 is most similar to that of ETEC E24377A of human origin and several other pathogenic E. coli strains. This variant was reported and characterized earlier, termed as subtype 2 (T6SS2) in APEC strains (Ma et al., 2013).

We also identified a truncated version of the type 2 of the type III secretions system (ETT2; (Makino et al., 2003). The yqe, yge, epr and epa gene clusters are present but the whole eiv gene cluster is missing albeit its flanking pseudogenes are present. (Fig. 2). The above gene clusters are integrated between a gene encoding a serine transporter and a glycine tRNA gene. This putative secretion system is widespread in pathogenic $E$. coli, and is thought to have regulatory functions in virulence in general (reviewed by Zhou et al., 2014).

T22 fulfils all the criteria of a CDT-producing E. coli (Tóth and Sváb, 2014) as demonstrated in our previous study (Taieb et al., 2015). CDTV from T22 caused characteristic morphological changes of HeLa cells 


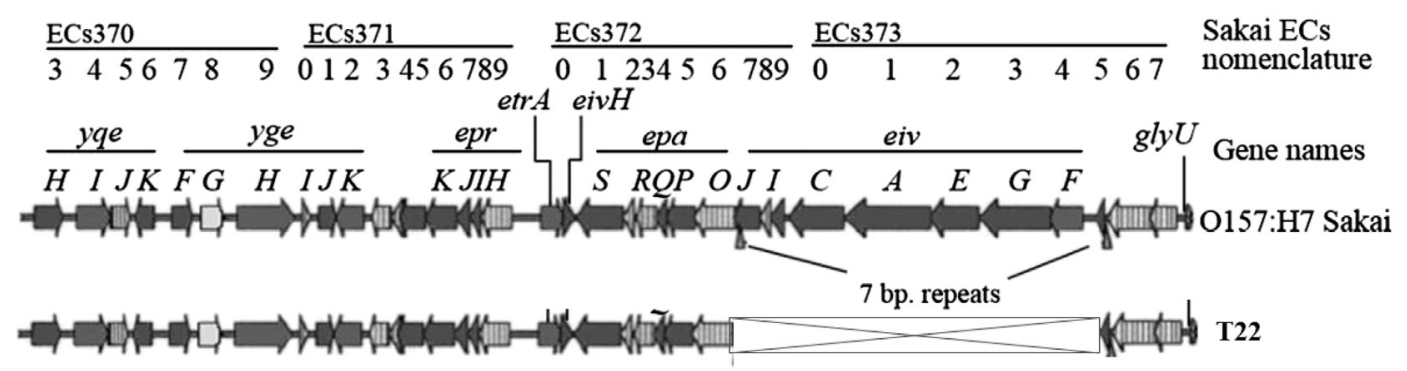

Chaperone $\square$ Transcriptional Regulator $\square$ Other PAI gene IIIII Pseudogene

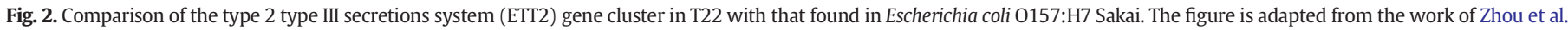

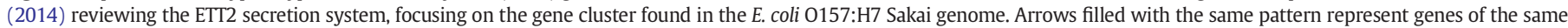
cluster.

in tissue culture assays. Cell cycle arrest of eukaryotic cells at G2-M2 transition was demonstrated by flow cytometry. In addition, the CDTinduced phosphorylation of histone protein H2AX was observed by immunoblot analysis revealing double-stranded DNA damage in the cells (Taieb et al., 2015). Recent studies suggest the distinction of cytolethal distending toxin producing $E$. coli as a pathotype on its own right, abbreviated as 'CTEC' (Hinenoya et al., 2009, 2014). While not being isolated from human source, and thus not having direct evidence for its pathogenicity, E. coli T22 can be categorized as CTEC, while also carrying the gene cluster encoding LT-II and the pertussis-like toxin.

\subsection{CRISPR regions}

Clustered regularly interspaced palindromic repeats (CRISPR) and the proteins encoded by the CRISPR-associated genes (Cas) are utilized by various archaea and bacteria (including E. coli) as an adaptive immune system against foreign genetic material reviewed in BondyDenomy and Davidson (2014). All four CRISPR regions (CRISPR1-4) identified up to date in $E$. coli are present. A summary of these regions is shown in Table 3.Thus the T22 genome contains a presumably functional CRISPR-Cas system. The CRISPR1 is coupled to the gene cluster encoding the Cas genes, which is most similar to the gene cluster carried by ETEC strain E24377A (Díez-Villaseñor et al., 2010).

The spacers in the CRISPR1 array of T22 are identical to those carried by strain hu24 and k8, isolated from human source (GenBank KF707537.1 and KF707515.1; (Sheludchenko et al., 2015). However, when compared to the repeat regions of typical 0157 EHEC strains (Delannoy et al., 2012), no common spacers can be observed.

The CRISPR2 region bears an overall similarity to that found in several K-12 and commensal strains. Comparison with the STEC CRISPR sequence collection deposited by Yin et al. (2013) revealed that the first and fourth spacer of T22 CRISPR2 are shared with the corresponding region of strain 0-0846, but no other matching spacers can be found. On the other hand all spacers of T22 CRISPR1 and CRISPR2 can be found in the corresponding regions of Shiga toxin-producing (STEC) 0113:H21 strains determined by Feng et al. (2014), and in several E. coli reference (ECOR) strains, albeit in different arrangements. Fig. 3 shows a schematic representation of CRISPR1 and CRISPR2.

It is interesting to note that according to Yin et al., a conservation of CRISPR sequences could be observed between 0157 strains carrying the

Table 3

Main characteristics of CRISPR regions in E. coli T22.

\begin{tabular}{llll}
\hline Region & Integration site & Number of spacers & Length of spacers (nt) \\
\hline CRISPR1 & $\begin{array}{l}\text { Cas2 and alkaline } \\
\text { phosphatase }\end{array}$ & 12 & $32^{\mathrm{a}}$ \\
CRISPR2 & ygcF, $y g c E$ & & \\
CRISPR3 & $c l p S$, aat & 26 & 32 \\
CRISPR4 & $c l p S$, aat & 0 & $\mathrm{~N} / \mathrm{A}$ \\
\end{tabular}

a One spacer in CRISPR1 is $33 \mathrm{nt}$ long. same $\mathrm{H}$ antigen (Yin et al., 2013). Recently the draft genome sequence of porcine ETEC 0157:H43 strain DEC7A became available (GenBank AIGA01000043.1, Hazen et al., 2012). However, when comparing the CRISPR1 and CRISPR2 regions of T22 to those of DEC7A, no matching spacers are found.

The CRISPR3 and CRISPR4 regions, in harmony with earlier findings (Touchon and Rocha, 2010), forms a combined, short, and apparently conserved array, which shows $100 \%$ identity to corresponding regions carried by more than $40 \mathrm{E}$. coli strains according to GenBank, and without containing any spacers (Toro et al., 2014).

\subsection{Phylogenetic relations}

To investigate the phylogenetic relationships of E. coli T22 to other pathogenic and non-pathogenic E. coli strains, we selected 62 publicly available whole genomes and compared them by core genome phylogeny. The selected strains represent all the main intestinal pathotypes as well as extraintestinal (ExPEC), uropathogenic (UPEC) and commensal strains. Representatives of the four species of Shigella were also included. The accession numbers of the genomes are given in Table A1. All the common conserved genes present in these E. coli and Shigella genomes were collected. DNA sequence for as many as 1862 common genes were identified and used in genome comparison analysis (Fig. 4).

The core genome phylogeny placed T22 closest to E24377A ETEC strain of 0139:H28 serotype, as well as the EHEC 026:H11 and 0111:NM strains. The EHEC 0103:H2 strain was placed on a neighboring branch. These three EHEC strains (designations 11,368, 11,128 and 120,009 , respectively) were isolated from sporadic cases of diarrhea (Ogura et al., 2007), while ETEC E24377A was isolated from drinking water (Tamhankar et al., 2015). The typical EHEC 0157:H7 strains and their ancestors, the 055:H7 strains (Feng et al., 2007) form a separate group, as well as the recently emerged 0104:H4 enteroaggregativehemorrhagic (EAHEC) strains. These results indicate that T22 belongs to a separate lineage of intestinal pathogenic strains, divergent from the typical 0157 EHEC and also from the recently emerged 0104:H4 EAHEC strains. Our phylogenetic analysis also showed that commensal strains like IAI1, SE15 and SMS-3-5 are widely distributed all along the tree. Extraintestinal strains are separate from all the above-mentioned clusters, but they are insterspersed with EPEC and other intestinal and commensal strains. The Shigella dysenteriae Sd197 strain was placed close to the EHEC 0157:H7 strains, but far from strains of other Shigella species (Fig. 4).

Complementary to the phylogenetic relations a further, gene-content based pangenome analysis was performed with the genomes of $E$. coli T22, the commensal E. coli strains IAI1, SE11 and the prototypic EHEC 0157:H7 EDL933 strain (GenBank no. CU928160.2, AP009240.1, and AE005174.2, respectively). The former two were chosen because on the whole-genome sequence level they are closest to T22 among the commensal strains, and the EDL933strain was included as prototypic EHEC 0157 strain. These analyses revealed 3,599CDSs (82\% of the T22 


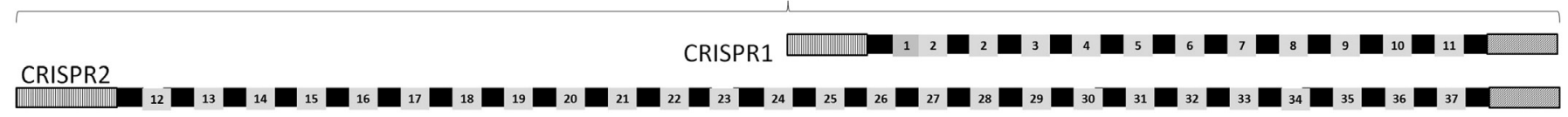

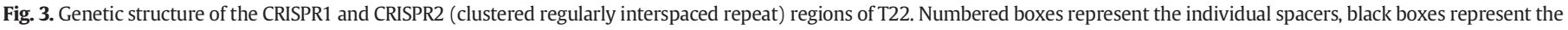
repeat sequences, the textured bars represent the leader and closing sequences, respectively. Note that in CRISPR1, spacer 2 is present in two copies.

CDSs) that are common to all four compared E. coli genomes, while 261 CDSs (6\%) are T22-specific (Fig. 5. and Table A2). T22-specific genes include the gene cluster encoding CDT, LT-II and EalAB, as well as several plasmid and prophage-related structural and regulatory genes in the chromosome. One gene of the O-antigen biosynthesis cluster is also included, which further supports the idea of T22 representing a distinct lineage from other 0157 strains, while this gene shows high identity percentage to that carried by the strain E. coli PV00-24, and of the 0157:H43 serotype (GenBank AB602253.1). This finding also confirms the notion that differences in the 0157 biosynthesis genes indicate the separation of lineages within the serogroup (Iguchi et al., 2011). 34 of the 261 unique genes are found on the plasmid pT22. These include the iron di-citrate transport system, the F-pilin as well as the tra and trb gene cluster related to the conjugative transfer. The predicted functions and closest homologues of the unique genes are summarized in Table A2.

All these results indicate that $E$. coli $\mathrm{T} 22$ represents a distinct evolutionary path from the typical STEC and EHEC members of the 0157 serogroup, and being divergent from enterotoxigenic E. coli (ETEC) strains of 0157:H43 serotype, although there is considerably fewer sequence data available for ETEC 0157 strains. In a recent study by Sanjar et al. (2015) phylogenetic analysis placed the genomes of 0157:non-H7 strains, including T22, apart from typical EHEC and EPEC strains of the serogroup, further suggesting its separate lineage. In harmony with our results Sanjar et al. reported that T22 clustered together with ETEC strain E24377A, commensal E. coli strain IAI1, and also with

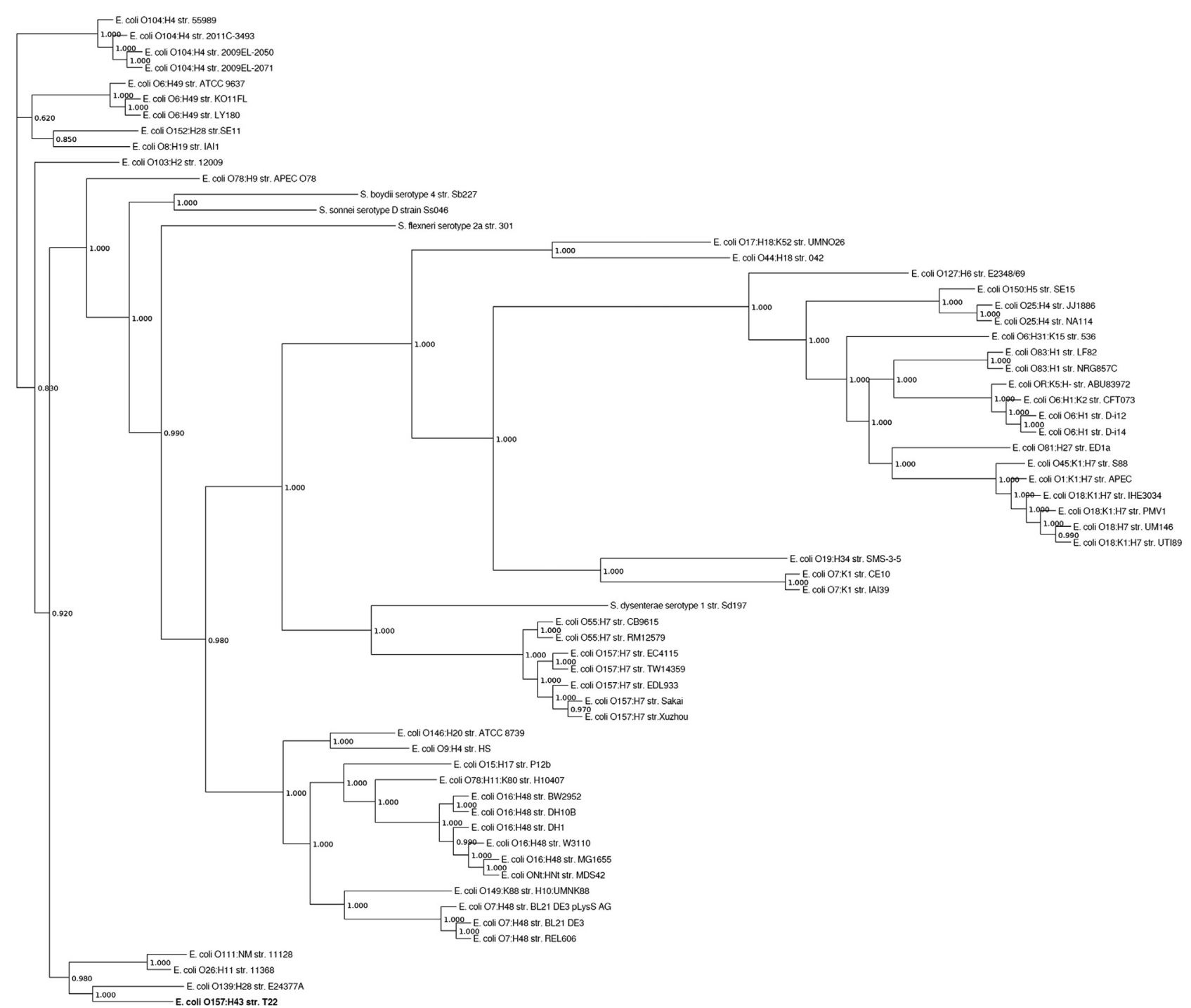

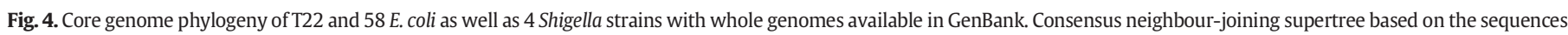
of 1862 common genes. 


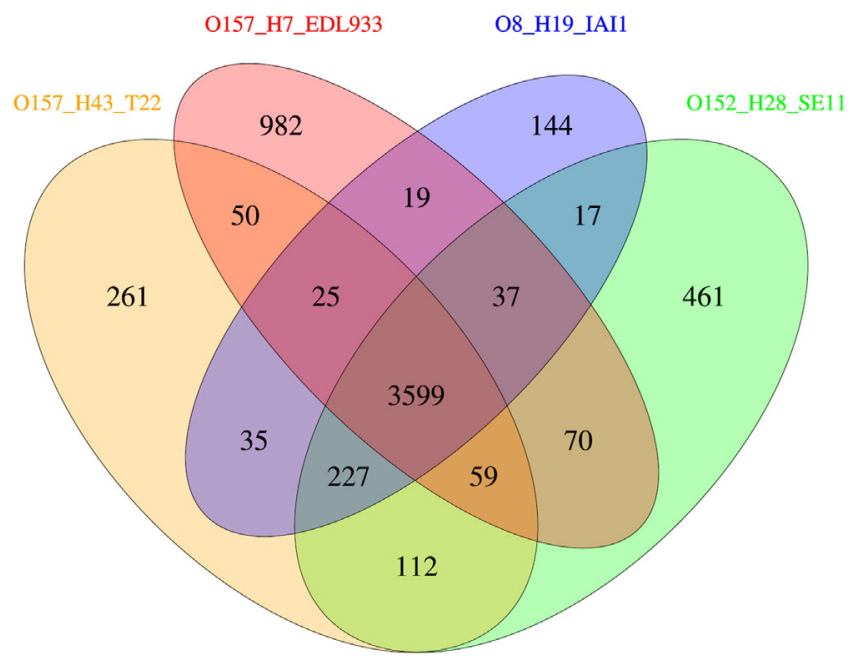

Fig. 5. Comparison of the genetic content of the sequenced E. coli 0157:H43 strain T22 with the EHEC 0157:H7 EDL933 strain and the commensal E. coli SE11 and IAI1 strains. The 4 strains share 3599 common genes and 261 specific genes were identified in the T22 genome. The T22 specific genes are listed in Table A2.

EHEC strains 11128,11368 and 120,009 . Together with the results of the pangenome analysis, these data strongly support the idea of T22 representing a unique and so far uncharacterized lineage of pathogenic E. coli (Figs. 4 and 5).

Since T22 represents a novel patho- and genotype among E. coli 0157 strains it is necessary to summarize the relation of T22 to prototypic EHEC 0157 strains regarding their phylogenetic markers. Earlier a step-wise evolution model was devised for the emergence of 0157:H7/NM EHEC strains (Feng et al., 2007). In this model, the inability to ferment sorbitol is considered a key marker of typical EHEC 0157:H7 strains. Interestingly, T22 also shows the non-sorbitolfermenting (NSF) phenotype (Tóth et al., 2009). In a more recent study, conducted with 4000157 strains including nine of the 0157:H43 strains, pulsed field gel electrophoresis (PFGE) patterns suggested that the 0157 serogroup became divergent according to the different $\mathrm{H}$ types (Rump et al., 2015). Out of the nine 0157:H43 strains investigated by Rump et al. (2015) only two were NSF, and one of theme lacked all EHEC-specific marker genes. Similarly, none of the 13 EHEC-specific marker genes are present in the genome of T22. Because the study was limited to these 13 genes, no further genetic comparison is possible at present between T22 and the 0157:H43 strains investigated by Rump et al. (2015).

\subsection{Conclusions}

EHEC 0157:H7/NM strains are well characterized dangerous zoonotic pathogens, but less information is available on E. coli 0157 strains with different virulence genes and $\mathrm{H}$ antigen. Here we present the first comprehensive genomic analysis of a CDT-producing, Stx- and intiminnegative E. coli 0157 strain, and the first whole genome of the 0157:H43 serotype. Our results show that besides CDT, T22 carries an array of additional virulence genes, including those encoding LT-II toxin as well as the type 1 fimbria and Lpf as potential adhesins. The genome contains large amount of prophages, one of them carries the $c d t$ and another the LT-II encoding genes. To our knowledge, no E. coli 0157 strain with similar genotype and virulence array has been described up to date in detail.

Regarding the phylogenetic relations of T22, our results indicate that it has a unique position among pathogenic and wild-type commensal $E$. coli strains, representing a separate lineage from the typical EHEC and EPEC 0157 strains. The lack of key EHEC virulence genes and the integrity of their typical integration hot spots further support this notion. The unique evolutionary background and genotype of T22 also calls the attention to the continuing emergence of new virulence gene combinations among $E$. coli of serogroup 0157.

\section{Acknowledgments}

This study was supported by the Hungarian Research Fund (OTKA grant no. K 81 252).

\section{Appendix A. Supplementary data}

Supplementary data to this article can be found online at doi:10. 1016/j.meegid.2016.11.003.

\section{References}

Ahmed, S.A., Awosika, J., Baldwin, C., Bishop-Lilly, K.A., Biswas, B., Broomall, S., Chain, P.S.G., Chertkov, O., Chokoshvili, O., Coyne, S., Davenport, K., Detter, J.C., Dorman, W., Erkkila, T.H., Folster, J.P., Frey, K.G., George, M., Gleasner, C., Henry, M., Hill, K.K., Hubbard, K., Insalaco, J., Johnson, S., Kitzmiller, A., Krepps, M., Lo, C.-C., Luu, T., McNew, L.A., Minogue, T., Munk, C.A., Osborne, B., Patel, M., Reitenga, K.G. Rosenzweig, C.N., Shea, A., Shen, X., Strockbine, N., Tarr, C., Teshima, H., van Gieson, E., Verratti, K., Wolcott, M., Xie, G., Sozhamannan, S., Gibbons, H.S., Threat Characterization Consortium, 2012. Genomic comparison of Escherichia coli 0104: H4 isolates from 2009 and 2011 reveals plasmid, and prophage heterogeneity, including shiga toxin encoding phage stx2. PLoS One 7, e48228. http://dx.doi.org/10. 1371/journal.pone.0048228.

Asadulghani, M., Ogura, Y., Ooka, T., Itoh, T., Sawaguchi, A., Iguchi, A., Nakayama, K. Hayashi, T., 2009. The defective prophage pool of Escherichia coli 0157: prophageprophage interactions potentiate horizontal transfer of virulence determinants. PLoS Pathog. 5, e1000408. http://dx.doi.org/10.1371/journal.ppat.1000408.

Bankevich, A., Nurk, S., Antipov, D., Gurevich, A.A., Dvorkin, M., Kulikov, A.S., Lesin, V.M. Nikolenko, S.I., Pham, S., Prjibelski, A.D., Pyshkin, A.V., Sirotkin, A.V., Vyahhi, N. Tesler, G., Alekseyev, M.A., Pevzner, P.A., 2012. SPAdes: a new genome assembly algorithm and its applications to single-cell sequencing. J. Comput. Biol. J. Comput. Mol Cell Biol. 19:455-477. http://dx.doi.org/10.1089/cmb.2012.0021.

Barondess, J.J., Beckwith, J., 1995. bor gene of phage lambda, involved in serum resistance, encodes a widely conserved outer membrane lipoprotein. J. Bacteriol. 177, 1247-1253.

Bobay, L.-M., Rocha, E.P.C., Touchon, M., 2013. The adaptation of temperate bacteriophages to their host genomes. Mol. Biol. Evol. 30:737-751. http://dx.doi.org/10. 1093/molbev/mss279.

Boetzer, M., Henkel, C.V., Jansen, H.J., Butler, D., Pirovano, W., 2011. Scaffolding pre-assembled contigs using SSPACE. Bioinforma. Oxf. Engl. 27:578-579. http://dx.doi.org 10.1093/bioinformatics/btq683.

Bondy-Denomy, J., Davidson, A.R., 2014. To acquire or resist: the complex biological effects of CRISPR-Cas systems. Trends Microbiol. 22:218-225. http://dx.doi.org/10. 1016/j.tim.2014.01.007.

Caprioli, A., Morabito, S., Brugère, H., Oswald, E., 2005. Enterohaemorrhagic Escherichia coli: emerging issues on virulence and modes of transmission. Vet. Res. 36: 289-311. http://dx.doi.org/10.1051/vetres:2005002.

Contreras-Monera, B., Vinuesa, P., 2013. GET_HOMOLOGUES, a versatile software package for scalable and robust microbial pangenome analysis. Appl. Environ. Microbiol. 79: 7696-7701. http://dx doi.org/10.1128/AEM.02411-13.

Delannoy, S., Beutin, L., Fach, P., 2012. Use of clustered regularly interspaced short palindromic repeat sequence polymorphisms for specific detection of enterohemorrhagic Escherichia coli strains of serotypes 026:H11, O45:H2, 0103:H2, 0111:H8, 0121:H19, 0145:H28, and 0157:H7 by real-time PCR. J. Clin. Microbiol. 50:4035-4040. http://dx. doi.org/10.1128/JCM.02097-12.

Díez-Villaseñor, C., Almendros, C., García-Martínez, J., Mojica, F.J.M., 2010. Diversity of CRISPR loci in Escherichia coli. Microbiol. (Read. Engl.) 156:1351-1361. http://dx doi.org/10.1099/mic.0.036046-0.

Eppinger, M., Daugherty, S., Agrawal, S., Galens, K., Sengamalay, N., Sadzewicz, L., Tallon, L., Cebula, T.A., Mammel, M.K., Feng, P., Soderlund, R., Tarr, P.I., Debroy, C., Dudley, E.G., Fraser, C.M., Ravel, J., 2013. Whole-genome draft sequences of 26 enterohemorrhagic Escherichia coli 0157:H7 strains. Genome Announc. 1, e0013412. http://dx.doi.org/10.1128/genomeA.00134-12.

Feng, P.C.H., Delannoy, S., Lacher, D.W., Dos Santos, L.F., Beutin, L., Fach, P., Rivas, M. Hartland, E.L., Paton, A.W., Guth, B.E.C., 2014. Genetic diversity and virulence potential of shiga toxin-producing Escherichia coli 0113:H21 strains isolated from clinical, environmental, and food sources. Appl. Environ. Microbiol. 80:4757-4763. http:// dx.doi.org/10.1128/AEM.01182-14.

Feng, P.C.H., Monday, S.R., Lacher, D.W., Allison, L., Siitonen, A., Keys, C., Eklund, M., Nagano, H., Karch, H., Keen, J., Whittam, T.S., 2007. Genetic diversity among clonal lineages within Escherichia coli 0157:H7 stepwise evolutionary model. Emerg. Infect Dis. 13:1701-1706. http://dx.doi.org/10.3201/eid1311.070381.

Gyles, C.L., 2007. Shiga toxin-producing Escherichia coli: an overview. J. Anim. Sci. 85: E45-E62. http://dx.doi.org/10.2527/jas.2006-508.

Hayashi, T., Makino, K., Ohnishi, M., Kurokawa, K., Ishii, K., Yokoyama, K., Han, C.G., Ohtsubo, E., Nakayama, K., Murata, T., Tanaka, M., Tobe, T., Iida, T., Takami, H., Honda, T., Sasakawa, C., Ogasawara, N., Yasunaga, T., Kuhara, S., Shiba, T., Hattori, M., Shinagawa, H., 2001. Complete genome sequence of enterohemorrhagic 
Escherichia coli 0157:H7 and genomic comparison with a laboratory strain K-12. DNA Res. Int. J. Rapid Publ. Rep. Genes Genomes 8, 11-22.

Hazen, T.H., Sahl, J.W., Fraser, C.M., Donnenberg, M.S., Scheutz, F., Rasko, D.A., 2013. Draft genome sequences of three 0157 enteropathogenic Escherichia coli isolates. Genome Announc. 1. http://dx.doi.org/10.1128/genomeA.00516-13.

Hazen, T.H., Sahl, J.W., Redman, J.C., Morris, C.R., Daugherty, S.C., Chibucos, M.C., Sengamalay, N.A., Fraser-Liggett, C.M., Steinsland, H., Whittam, T.S., Whittam, B. Manning, S.D., Rasko, D.A., 2012. Draft genome sequences of the diarrheagenic Escherichia coli collection. J. Bacteriol. 194:3026-3027. http://dx.doi.org/10.1128/JB. 00426-12.

Hinenoya, A., Naigita, A., Ninomiya, K., Asakura, M., Shima, K., Seto, K., Tsukamoto, T. Ramamurthy, T., Faruque, S.M. Yamasaki, S, 2009. Prevalence and characteristics of cytolethal distending toxin-producing Escherichia coli from children with diarrhea in Japan. Microbiol. Immunol. 53, 206-215.

Hinenoya, A., Shima, K., Asakura, M., Nishimura, K., Tsukamoto, T., Ooka, T., Hayashi, T. Ramamurthy, T., Faruque, S.M., Yamasaki, S., 2014. Molecular characterization of cytolethal distending toxin gene-positive Escherichia coli from healthy cattle and swine in Nara. Japan. BMC Microbiol. 14:97. http://dx.doi.org/10.1186/1471-2180 14-97.

Iguchi, A., Shirai, H., Seto, K., Ooka, T., Ogura, Y., Hayashi, T., Osawa, K., Osawa, R., 2011 Wide distribution of 0157-antigen biosynthesis gene clusters in Escherichia coli. PLoS One 6, e23250. http://dx.doi.org/10.1371/journal.pone.0023250.

Jehl, M.-A., Arnold, R., Rattei, T., 2011. Effective-a database of predicted secreted bacteria proteins. Nucleic Acids Res. 39:D591-D595. http://dx.doi.org/10.1093/nar/gkq1154.

Jobling, M.G., 2016. The chromosomal nature of LT-II enterotoxins solved: a lambdoid prophage encodes both LT-II and one of two novel pertussis-toxin-like toxin family members in type II enterotoxigenic Escherichia coli. Pathog. Dis. 74. http://dx.doi. org/10.1093/femspd/ftw001.

Jobling, M.G., Holmes, R.K., 2012. Type II heat-labile enterotoxins from 50 diverse Escherichia coli isolates belong almost exclusively to the LT-IIc family and may be prophage encoded. PLoS One 7, e29898. http://dx.doi.org/10.1371/journal.pone. 0029898 .

Kaper, J.B., Nataro, J.P., Mobley, H.L., 2004. Pathogenic Escherichia coli. Nat. Rev. Microbiol. 2:123-140. http://dx.doi.org/10.1038/nrmicro818.

Kleinheinz, K.A., Joensen, K.G., Larsen, M.V., 2014. Applying the ResFinder and VirulenceFinder web-services for easy identification of acquired antibiotic resistance and $E$. coli virulence genes in bacteriophage and prophage nucleotide sequences. Bacteriophage:4 http://dx.doi.org/10.4161/bact.27943.

Leiman, P.G., Basler, M., Ramagopal, U.A., Bonanno, J.B., Sauder, J.M., Pukatzki, S., Burley, S.K., Almo, S.C., Mekalanos, J.J., 2009. Type VI secretion apparatus and phage tail-associated protein complexes share a common evolutionary origin. Proc. Natl. Acad. Sci. U. S. A. 106:4154-4159. http://dx.doi.org/10.1073/pnas.0813360106.

Lloyd, S.J., Ritchie, J.M., Rojas-Lopez, M., Blumentritt, C.A., Popov, V.L., Greenwich, J.L., Waldor, M.K., Torres, A.G., 2012. A double, long polar fimbria mutant of Escherichi coli 0157:H7 expresses Curli and exhibits reduced in vivo colonization. Infect. Immun. 80:914-920. http://dx.doi.org/10.1128/IAI.05945-11.

Ma, J., Sun, M., Bao, Y., Pan, Z., Zhang, W., Lu, C., Yao, H., 2013. Genetic diversity and features analysis of type VI secretion systems loci in avian pathogenic Escherichia coli by wide genomic scanning. Infect. Genet. Evol. J. Mol. Epidemiol. Evol. Genet. Infect. Dis. 20:454-464. http://dx.doi.org/10.1016/j.meegid.2013.09.031.

Makino, S.-I., Tobe, T., Asakura, H., Watarai, M., Ikeda, T., Takeshi, K., Sasakawa, C., 2003. Distribution of the secondary type III secretion system locus found in enterohemorrhagic Escherichia coli 0157:H7 isolates among Shiga toxin-producing E. coli strains. J. Clin. Microbiol. 41, 2341-2347.

Martinez, J.J., Mulvey, M.A., Schilling, J.D., Pinkner, J.S., Hultgren, S.J., 2000. Type 1 pilusmediated bacterial invasion of bladder epithelial cells. EMBO J. 19:2803-2812. http://dx.doi.org/10.1093/emboj/19.12.2803.

Muniesa, M., Recktenwald, J., Bielaszewska, M., Karch, H., Schmidt, H., 2000. Characterization of a shiga toxin 2e-converting bacteriophage from an Escherichia coli strain of human origin. Infect. Immun. 68, 4850-4855.

Nilsson, H., Cardoso-Palacios, C., Haggård-Ljungquist, E., Nilsson, A.S., 2011. Phylogenetic structure and evolution of regulatory genes and integrases of P2-like phages. Bacteriophage 1:207-218. http://dx.doi.org/10.4161/bact.1.4.18470.

Ogura, Y., Ooka, T., Asadulghani, T., Nougayréde, J., Kurokawa, K., Tashiro, K., Tobe, T. Nakayama, K., Kuhara, S., Oswald, E., Watanabe, H., Hayashi, T., 2007. Extensive genomic diversity and selective conservation of virulence determinants in enterohemorrhagic Escherichia coli strains of 0157 and non-0157 serotypes. Genome Biol. 8:R138. http://dx.doi.org/10.1186/gb-2007-8-7-r138.

Perna, N.T., Glasner, J.D., Burland, V., Plunkett III, G., 2002. The genomes of Escherichia coli K-12 and pathogenic E. coli. In: Donnenberg, M.S. (Ed.), Escherichia coli. Virulence Mechanisms of a Versatile Pathogen. Elsevier Science, San Diego, pp. 3-53.

Perna, N.T., Plunkett, G., Burland, V., Mau, B., Glasner, J.D., Rose, D.J., Mayhew, G.F., Evans, P.S., Gregor, J., Kirkpatrick, H.A., Pósfai, G., Hackett, J., Klink, S., Boutin, A., Shao, Y., Miller, L., Grotbeck, E.J., Davis, N.W., Lim, A., Dimalanta, E.T., Potamousis, K.D. Apodaca, J Anantharaman, T.S., Lin, J., Yen, G., Schwartz, D.C., Welch, R.A., Blattner, F.R., 2001. Genome sequence of enterohaemorrhagic Escherichia coli 0157:H7. Nature 409:529-533. http://dx.doi.org/10.1038/35054089.

Price, M.N., Dehal, P.S., Arkin, A.P., 2010. FastTree 2-approximately maximum-likelihood trees for large alignments. PLoS One 5, e9490. http://dx.doi.org/10.1371/journal.pone. 0009490.

Recktenwald, J., Schmidt, H., 2002. The nucleotide sequence of Shiga toxin (Stx) 2eencoding phage phiP27 is not related to other Stx phage genomes, but the modula genetic structure is conserved. Infect. Immun. 70, 1896-1908.

Rice, P., Longden, I., Bleasby, A., 2000. EMBOSS: the European molecular biology open software suite. Trends Genet. TIG 16, 276-277.
Rump, L.V., Gonzalez-Escalona, N., Ju, W., Wang, F., Cao, G., Meng, S., Meng, J., 2015. Genomic diversity and virulence profiles of historical Escherichia coli 0157 strains isolated from clinical and environmental sources. Appl. Environ. Microbiol. 81:569-577. http://dx.doi.org/10.1128/AEM.02616-14.

Saitoh, M., Tanaka, K., Nishimori, K., Makino, S., Kanno, T., Ishihara, R., Hatama, S., Kitano, R., Kishima, M., Sameshima, T., Akiba, M., Nakazawa, M., Yokomizo, Y., Uchida, I., 2005. The artAB genes encode a putative ADP-ribosyltransferase toxin homologue associated with Salmonella enterica serovar Typhimurium DT104. Microbiol. (Read. Engl.) 151:3089-3096. http://dx.doi.org/10.1099/mic.0.27933-0.

Sanjar, F., Rusconi, B., Hazen, T.H., Koenig, S.S.K., Mammel, M.K., Feng, P.C.H., Rasko, D.A., Eppinger, M., 2015. Characterization of the pathogenome and phylogenomic classification of enteropathogenic Escherichia coli of the 0157:non-H7 serotypes. Pathog. Dis. 73. http://dx.doi.org/10.1093/femspd/ftv033.

Seemann, T., 2014. Prokka: rapid prokaryotic genome annotation. Bioinforma. Oxf. Engl. 30:2068-2069. http://dx.doi.org/10.1093/bioinformatics/btu153.

Sheludchenko, M.S., Huygens, F., Stratton, H., Hargreaves, M., 2015. CRISPR diversity in E. coli isolates from Australian animals, humans and environmental waters. PloS One 10, e0124090. http://dx.doi.org/10.1371/journal.pone.0124090.

Stephan, R., Borel, N., Zweifel, C., Blanco, M., Blanco, J.E., 2004. First isolation and further characterization of enteropathogenic Escherichia coli (EPEC) 0157:H45 strains from cattle. BMC Microbiol. 4:10. http://dx.doi.org/10.1186/1471-2180-4-10.

Sváb, D., Tóth, I., 2012. Allelic types of long polar fimbriae in bovine and human Escherichia coli 0157 strains. Acta Vet. Hung. 60:1-15. http://dx.doi.org/10.1556/ AVet.2012.001.

Sváb, D., Horváth, B., Maróti, G., Dobrindt, U., Tóth, I., 2013a. Sequence variability of P2like prophage genomes carrying the cytolethal distending toxin $\mathrm{V}$ operon in Escherichia coli 0157. Appl. Environ. Microbiol. 79:4958-4964. http://dx.doi.org/10. 1128/AEM.01134-13.

Sváb, D., Horváth, B., Szucs, A., Maróti, G., Tóth, I., 2013b. Draft genome sequence of an Escherichia coli 0157:H43 strain isolated from cattle. Genome Announc. 1. http://dx. doi.org/10.1128/genomeA.00263-13.

Tabei, Y., Kiryu, H., Kin, T., Asai, K., 2008. A fast structural multiple alignment method for long RNA sequences. BMC Bioinf. 9:33. http://dx.doi.org/10.1186/1471-2105-9-33.

Taieb, F., Sváb, D., Watrin, C., Oswald, E., Tóth, I., 2015. Cytolethal distending toxin A, B and C subunit proteins are necessary for the genotoxic effect of Escherichia coli CDT-V. Acta Vet Hung. 63:1-10. http://dx.doi.org/10.1556/AVet.2015.001.

Tamhankar, A.J., Nerkar, S.S., Khadake, P.P., Akolkar, D.B., Apurwa, S.R., Deshpande, U., Khedkar, S.U., Stalsby-Lundborg, C., 2015. Draft genome sequence of enterotoxigenic Escherichia coli strain E24377A, obtained from tribal drinking water source in India. Genome Announc. 3, e00225-15. http://dx.doi.org/10.1128/genomeA.00225-15.

Toro, M., Cao, G., Ju, W., Allard, M., Barrangou, R., Zhao, S., Brown, E., Meng, J., 2014. Association of clustered regularly interspaced short palindromic repeat (CRISPR) elements with specific serotypes and virulence potential of shiga toxin-producing Escherichia coli. Appl. Environ. Microbiol. 80:1411-1420. http://dx.doi.org/10.1128/ AEM.03018-13.

Torres, A.G., Blanco, M., Valenzuela, P., Slater, T.M., Patel, S.D., Dahbi, G., López, C., Barriga, X.F. Blanco, J.E., Gomes, T.A.T., Vidal, R., Blanco, J., 2009. Genes related to long polar fimbriae of pathogenic Escherichia coli strains as reliable markers to identify virulent isolates. J. Clin. Microbiol. 47:2442-2451. http://dx.doi.org/10.1128/JCM.00566-09.

Torres, A.G., Giron, J.A., Perna, N.T., Burland, V., Blattner, F.R., Avelino-Flores, F., Kaper, J.B. 2002. Identification and characterization of $\operatorname{lpf} A B C C^{\prime} D E$, a fimbrial operon of enterohemorrhagic Escherichia coli 0157:H7. Infect. Immun. 70, 5416-5427.

Tóth, I., Sváb, D., 2014. Cell cycle modulating toxins produced by Escherichia coli. In: Morabito, S. (Ed.), Pathogenic Escherichia coli. Caister Academic Press, Norfolk, pp. $117-138$

Tóth, I., Schmidt, H., Kardos, G., Lancz, Z., Creuzburg, K., Damjanova, I., Pászti, J., Beutin, L., Nagy, B., 2009. Virulence genes and molecular typing of different groups of Escherichia coli 0157 strains in cattle. Appl. Environ. Microbiol. 75:6282-6291. http://dx.doi.org/10.1128/AEM.00873-09.

Touchon, M., Rocha, E.P.C., 2010. The small, slow and specialized CRISPR and anti-CRISPR of Escherichia and Salmonella. PLoS One 5, e11126. http://dx.doi.org/10.1371/journal. pone.0011126.

Vica Pacheco, S., García González, O., Paniagua Contreras, G.L., 1997. The lom gene of bacteriophage lambda is involved in Escherichia coli K12 adhesion to human buccal epithelial cells. FEMS Microbiol. Lett. 156, 129-132.

Wyrsch, E., Roy Chowdhury, P., Abraham, S., Santos, J., Darling, A.E., Charles, I.G., Chapman, T.A., Djordjevic, S.P., 2015. Comparative genomic analysis of a multiple antimicrobial resistant enterotoxigenic E. coli 0157 lineage from Australian pigs. BMC Genomics 16:165. http://dx.doi.org/10.1186/s12864-015-1382-y.

Yin, S., Jensen, M.A., Bai, J., Debroy, C., Barrangou, R., Dudley, E.G., 2013. The evolutionary divergence of Shiga toxin-producing Escherichia coli is reflected in clustered regularly interspaced short palindromic repeat (CRISPR) spacer composition. Appl. Environ. Microbiol. 79:5710-5720. http://dx.doi.org/10.1128/AEM.00950-13.

Zhou, M., Guo, Z., Duan, Q., Hardwidge, P.R., Zhu, G., 2014. Escherichia coli type III secretion system 2: a new kind of T3SS? Vet. Res. 45:32. http://dx.doi.org/10.1186/1297-971645-32.

Zhou, Y., Liang, Y., Lynch, K.H., Dennis, J.J., Wishart, D.S., 2011. PHAST: a fast phage search tool. Nucleic Acids Res. 39:W347-W352. http://dx.doi.org/10.1093/nar/gkr485.

\section{Web references}

Illumina Inc., r. http://www.illumina.com/documents/products/technotes/technote_ nextera_matepair_data_processing.pdf (accessed: 8th June 2016). 